\section{Subcapsular hepatic hematoma post ERCP: a rare or an underdiagnosed complication?}

Endoscopic retrograde cholangiopancreatography (ERCP) is a minimally invasive procedure for diagnosis and treatment of biliary and pancreatic disease that even in expert hands can have complications in $2 \%-10 \%$ of cases, with mortality rates of $0.5 \%-1 \%[1,2]$. Pancreatitis, cholangitis, perforation, and bleeding from papillotomy have been the most frequently described complications.

Subcapsular hepatic hematoma is a rare complication following ERCP. The first report was in 2001 by Ortega et al. [1], and since then only a few cases have been described worldwide. We present a series of three cases of subcapsular hepatic hematoma post ERCP, treated at our institution in a 5-year period.

Case \#1. A 96-year-old with a periampullary tumor with biliary obstruction underwent ERCP for biopsies and biliary plastic stent placement. At 4 hours post-procedure, the patient complained of right shoulder pain, with no other symptoms and no findings in the physical examination. Amylase and lipase were in the normal range. A computed tomography (CT) scan was performed, and this showed a subcapsular hepatic hematoma measuring $17 \times 13 \times 5 \mathrm{~cm}$ with central pneumobilia in the right hepatic lobe ( $\bullet$ Fig. 1 ). The patient was hemodynamically stable, and was conservatively managed, with analgesia and broad spectrum antibiotics. The evolution was uneventful, the follow-up CT showed complete resolution of the hematoma, and the patient was discharged 9 days after the admission.

Case \#2. A 49-year-old man had previously had surgery for testicular cancer in 1996 and had acute pancreatitis in 2006. ERCP had been performed because of suspicion of chronic autoimmune pancreatitis, with biliary plastic stenting and two stent replacements since January 2007. The patient suffered a new episode of biliary stent occlusion, confirmed with liver function tests, CT, and magnetic resonance imaging (MRI), and underwent ERCPs with uneventful stent exchange. At 2 hours post-procedure, the patient complained of right upper quadrant abdominal pain, hypotension, and tachycardia that improved with fluid volume. The abdomen was tender in the right hypochondrium with no peritoneal signs. Abdominal CT showed a subcapsular hepatic hematoma covering $50 \%$ of the total hepatic volume. Hypotension persisted, and a further CT showed a free rupture to the peritoneal cavity with hemoperitoneum ( Fig.2). Angioembolization of the right hepatic artery was done, with peritoneal drainage under CT guidance, of $1950 \mathrm{~mL}$ of blood.

The patient recovered with progressive reduction of the drainage flow, and complete resolution of the hematoma was seen at another CT scan. The drainage was withdrawn on the 7th day after admission and the patient was discharged.

Case \#3. A 55-year-old woman had undergone operation for gallbladder cancer in 2007 with adjuvant chemoradiotherapy, and had biliary plastic stenting for malignant biliary obstruction; the stent had been replaced four times. The patient was admitted with biliary stent dysfunction and underwent ERCP with uneventful biliary plastic stent exchange. She then presented progressive abdominal and right shoulder pain. An abdominal CT was performed that showed a right subcapsular hepatic hematoma covering 30\% of the total hepatic volume ( $\bullet$ Fig. 3 ). This was conservatively managed. The check CT scan showed complete resolution and the patient was discharged.

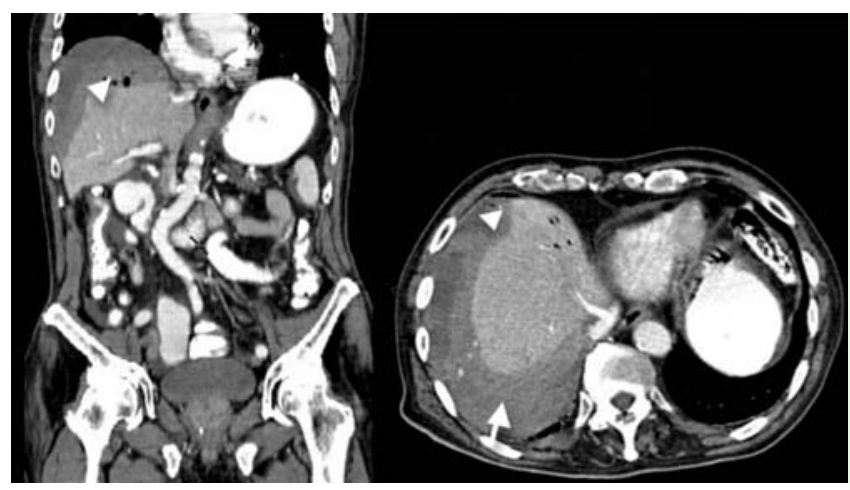

Fig. 1 Large subcapsular hepatic hematoma with air inside, in a 96-year-old man, seen at computed tomography $(\mathrm{CT})$ following endoscopic retrograde cholangiopancreatography (ERCP).

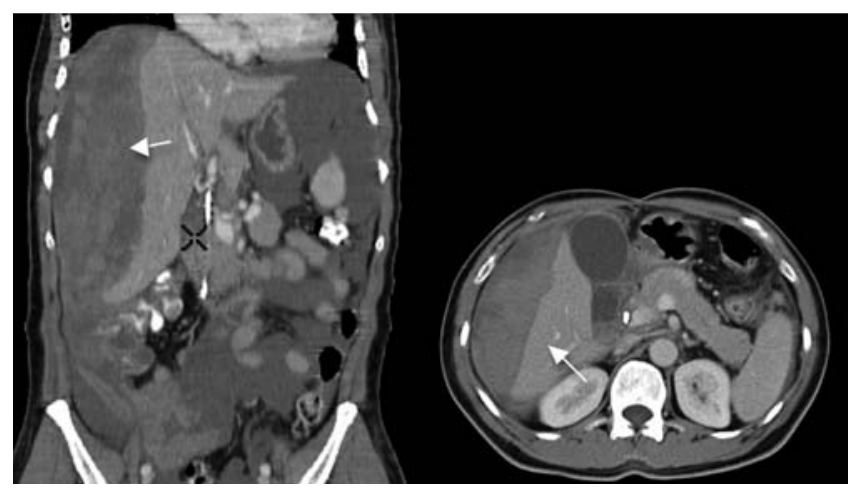

Fig. 2 Large subcapsular hepatic hematoma (arrows) in a 49-year-old man, seen at computed tomography $(\mathrm{CT})$ following endoscopic retrograde cholangiopancreatography (ERCP).

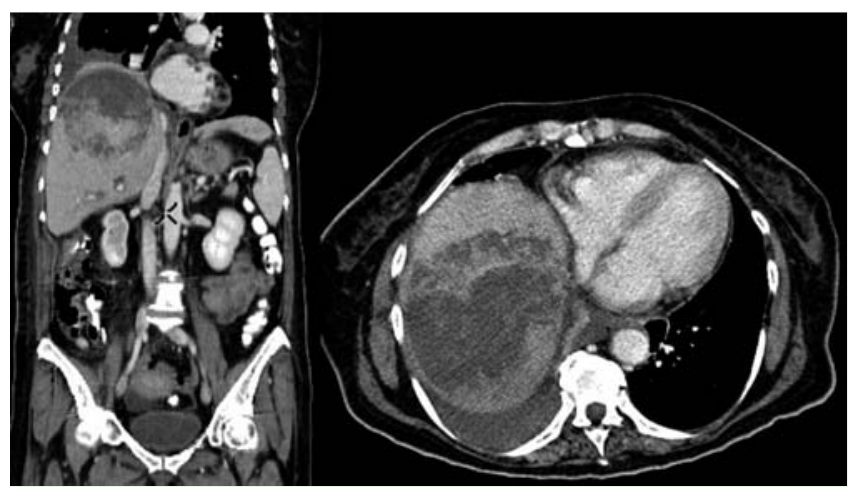

Fig. 3 Subcapsular hepatic hematoma in a 55-year-old woman, seen at computed tomography (CT) following endoscopic retrograde cholangiopancreatography (ERCP). 
ERCP is a diagnostic and therapeutic procedure that has become the treatment of choice for management of biliary tract diseases, although MRI has gained ground as a diagnostic procedure in recent times. Even in experienced hands, it has a $10 \%$ morbidity rate overall and a $1.5 \%$ mortality rate [2].

Subcapsular hepatic hematoma is a rare complication of ERCP, and only few cases have been reported in the literature. The low incidence of this complication may be explained by underdiagnosis of the injury because post-ERCP monitoring by imaging is not routinely done $[3,4]$.

Hematoma would occur as a result of accidental laceration or rupture of a small caliber intrahepatic vessel by the tip of the guide wire. This also explains the existence of air inside the hematoma and the frequency of infections, as use of the guide wire is not a sterile technique $[5,6]$. The occurrence of sudden-onset abdominal pain or hypotension post-procedure should raise the suspicion of this complication. Laboratory investigations do not provide major indicators of the development of subcapsular hepatic hematoma, except by a fall in hematocrit. Imaging modalities (ultrasound, CT, and MRI) are the methods of choice for the diagnosis and surveillance of this complication [79].

At our institution, 796 ERCPs have been carried out in a 5-year period between 2003 and 2009, and three cases of subcapsular hepatic hematoma have been diagnosed $(0.37 \%)$. Of these, two were managed conservatively, and one with angioembolization and peritoneal drainage under CT guidance, because of sponta- neous rupture and secondary hemodynamic compromise. The outcome was excellent and all the patients involved were discharged in good condition. There is only one report in the literature of surgical management. This describes a good patient outcome; but the report concludes that the case could have been conservatively managed [10].

\section{Endoscopy_UCTN_Code_TTT_1AR_2AK}

\section{Competing interests: None}

\section{F. Orellana ${ }^{1,2,3}$, J. Irarrazaval ${ }^{3}$,} J. Galindo ${ }^{3}$, P. Balbontin ${ }^{2}$, L. Manríquez $^{1}$, R. Plass ${ }^{1}$, R. Araya ${ }^{2}$, H. Ríos ${ }^{1}$, R. Sáenz ${ }^{4}$

${ }^{1}$ Department of Surgery, Hospital Militar de Santiago, Chile

2 Department of Gastroenterology, Hospital Militar de Santiago, Chile

${ }^{3}$ Department of Surgery, Universidad de Los Andes, Santiago, Chile

${ }^{4}$ Department of Gastroenterology, Clínica Alemana, Santiago, Chile

\section{References}

1 Ortega Deballon P, Fernández Lobato R, García Septiem J et al. Liver hematoma following endoscopic retrograde cholangiopancreatography (ERCP). Surg Endosc 2000; 14: 767

2 Hart R, Classen M. Complications of diagnostic gastrointestinal endoscopy. Endoscopy 1990; 22: 229-233

3 Horn TL, Pena LR. Subcapsular hepatic hematoma after ERCP: case report and review. Gastrointest Endosc 2004; 59: 594-596

4 Ertuğrul I, Parlak E, Ibis M et al. An unusual complication of endoscopic retrograde chol- angiopancreatography. Dig Dis Sci 2006; 51 : $1167-1168$

5 Petit-Laurent F, Scalone 0 , Penigaud $M$ et al. Sub-capsular hepatic hematoma after ERCP: case report and literature review. Gastroenterol Clin Biol 2007; 31: 750 - 752

6 De La Serna-Higuera C, Fuentes A, Rodríguez $S$. Hematoma hepático subcapsular secundario al empleo de una guía hidrofílica durante una colangio-pancreatografía retrógrada endoscópica. Gastroenterol Hepatol 2008; 31: 264-267

7 Priego P, Rodríguez G, Mena A et al. Hematoma sub-capsular hepático tras CPRE. Rev Esp Enf Ap Dig 2007; 99: 53 -54

8 Nari G, Preciado J, Rosendo N. A rare complication of ERCP: sub-capsular liver haematoma. Cir Esp 2009; 85: 253-263

9 Chi KD, Waxman I. Sub-capsular hepatic hematoma after guide-wire injury during endoscopic retrograde cholangiopancreatography: management and review. Endoscopy 2004; 36: 1019-1021

10 Bhati CS, Inston N, Wigmore SJ. Subcapsular intrahepatic hematoma: an unusual complication of ERCP. Endoscopy 2007; 39: E150

Bibliography

DOI http://dx.doi.org/ 10.1055/s-0031-1291493

Endoscopy 2012; 44: E108-E109

(c) Georg Thieme Verlag KG

Stuttgart · New York

ISSN 0013-726X

\section{Corresponding author}

\section{F. Orellana Gárate, MD}

Surgery Department

Hospital Militar de Santiago

Av. Larraín 9100, La Reina

Santiago

Chile

Fax: +56-2-8811374

fforella@gmail.com 